\title{
Elicitation of Hidden Expectations of Customers in Healthcare Service
}

\author{
Nandini $K^{1}$, Dr. A. C. Lokesh ${ }^{2}$ \\ ${ }^{1}$ Ph.D. Scholar, Ramaiah University of Applied Sciences, New BEL Road, Bangalore-560054 \\ ${ }^{2}$ Associate Professor and Head of the Department of Food Technology, Ramaiah University of Applied \\ Sciences, New BEL Road, Bangalore-560054
}

Corresponding Author: Nandini K

\begin{abstract}
In healthcare service, the customer feedback is often incomplete unless the unexpressed expectations are captured at the right time. These latent feelings and opinions are the 'hidden expectations' which are the quality indicators of the service offered. This short communication paper describes a couple of techniques for elicitation of hidden expectations of customers in the context of healthcare services. As an illustration, the paper depicts the application of these techniques for identification and prioritization of hidden expectations at a diagnostic center. Any organization in healthcare service sector could employ these techniques quickly and conveniently to improve quality of service thereby enhancing customer satisfaction.
\end{abstract}

Key Words: Elicitation, Customer satisfaction, Hidden expectation, MoSCoW, Healthcare

\section{INTRODUCTION}

In India, healthcare service is considered as a sunshine industry. Growing popularity and immense demand for affordable and quality patient-care has made India, the hub of medical tourism and telemedicine. However, with advancement in medical science and increase in healthcare awareness, customer expectations continue to demand perfection in day-to-day service.

Patient is the prime customer in the healthcare sector. Usually, 'customer satisfaction' finds its expression through feedback forms, suggestions and complaints. But there may be hidden expectations of customers which may remain un-expressed. These hidden expectations are instrumental in determining the 'Quality of Service' and aid to measure the extent of customer satisfaction. Hence elicitation of hidden expectations of customers assumes greater importance in achieving operational excellence.

Elicitation of customer expectations is all about bringing forth emotions, opinions, feelings and facts. It is the first step towards arriving at decision-maker's preferences. Fundamentally it involves identification of information and prioritizing them for decision analysis.

This short communication paper depicts about the 'observation' and 'interaction' techniques for identification of hidden expectations, followed by leveraging of MoSCoW technique for prioritization. Adoption of these techniques is backed by the outcomes of an exercise undertaken at a medical diagnostic centre.

\section{Identification of hidden expectations:}

Feedback forms and questionnaires are the traditional modes of getting responses of customers. Through these modes, customers may answer for the specific aspects of service. But they may still be having some more latent opinions, which they may not disclose due to apprehensions, lack of time or may not have any platform to do so. Hence top management of the organization could 
employ the following techniques to arrive at the hidden expectations of customers.

\section{(i) Observations:}

Involvement of workforce in day-today activities, style of functioning of staff members, dialogues and reactions of people, expressions of mood and tone of customers, repeated errors and mistakes by the staff are best captured through keen observations by the ethnographers.

\section{(ii) Interactions:}

The hidden and unexpressed feelings of the customers and the staff could be tapped through interactions. Interactions would also help to make sure that the observational outcomes are imperative and significant.

Although observation and interaction techniques seem to be simple and handy, these must be carried out by observation experts and interview specialists for efficient elicitation of customer expectations. In the absence of these professionals in the labs, existing senior staff like canter manager or operational executive could be trained to acquire these soft skills.

\section{Prioritization of hidden expectations:}

Hidden expectations thus identified need to be prioritized for acting on them based on their importance as perceived by the customers. The act of prioritization must therefore classify the needs and wants of customers into various groups. MoSCoW is one such prioritization technique developed by Dai Clegg of Oracle in 1994. This is a prioritization technique to reach a common understanding with stakeholders on the importance they place for the delivery of each requirement. This is a method used to sequence the needful expectations of stakeholders on their importance, necessity, frequency of their occurrence and the value they provide. This technique eventually yields four levels of priority needs namely 'Must have', 'Should have, 'Could have' and 'Wouldn't have' aspects. These aspects of MoSCoW technique have been summarized in the Table 1.

Table 1. MoSCoW Prioritization Levels

\begin{tabular}{|l|l|}
\hline $\begin{array}{l}\text { Prioritization } \\
\text { Level }\end{array}$ & Aspects of customer expectations \\
\hline Must Have & $\begin{array}{l}\text { Always used features; Show-Stoppers; Cannot } \\
\text { be compromised with needs; Very High Value } \\
\text { for the customer }\end{array}$ \\
\hline Should Have & $\begin{array}{l}\text { Frequently used; High Value for Customer; } \\
\text { Not Show-Stoppers but very much preferred } \\
\text { features }\end{array}$ \\
\hline Could Have & $\begin{array}{l}\text { Sometimes or rarely used; Feel good factors; } \\
\text { Not at all a Show-Stopper; Low Value for the } \\
\text { customer }\end{array}$ \\
\hline Wouldn't Have & $\begin{array}{l}\text { Should not be there; Rejections; Irritation } \\
\text { causers; No Value for Customers }\end{array}$ \\
\hline
\end{tabular}

\section{Exercise undertaken at ' $\mathrm{XYZ}$ Diagnostic} Centre':

Health care is a human right. Healthcare is an association of several departments and specializations. Medical Diagnostics is one such department that helps in diagnosis of illness that may be present. Literature survey about this basic and fundamental department reveals that research focus has been largely on pathological aspects rather than understanding customer expectations. Operational aspects that are crucial for routine and day-to-day activities of diagnostic labs are seldom addressed by researchers.

The present research paper discusses about an exercise carried out at ' $\mathrm{XYZ}$ Diagnostic Centre', to arrive at the hidden expectations of the customers. The ' $\mathrm{XYZ}$ Diagnostic Centre' is a self-sufficient and advanced healthcare setup with high end infrastructure and facilities medical diagnostic services. Delivery of high-quality service and expanding its brand image is the mission of the said diagnostic center. (Note: Name of the organization is not disclosed as per company regulations; instead referred as 'XYZ Diagnostics Centre' in this paper)

As the elicitation of hidden expectations was the intent of this exercise, 'observation' and 'interaction' techniques were found apt for gathering the expectations. Since reception desk is the first 'Point of Service' for patients, "Front Office" was selected as the department about which hidden expectations were 
captured. Then, these were prioritized using MoSCoW technique. Given below are the outcomes of the said exercise.

Must have characteristics are of very high value for the customers and cannot be compromised kind of features. They are 'always required feelings' of the customer. Following hidden expectations were gathered at 'XYZ Diagnostic Centre' as 'Must have' needs.

\section{Front office workforce}

- must be compassionate and sympathetic towards needy and sick patient and receive them in a humble way

- must be knowledgeable and competent about the lab activities

- must give clear and correct instructions and information to the patients

- must respond well to phone calls, emails

- must connect to respective doctors in case of emergency

- must inform patients about home collection facility to collect investigation samples

- must inform about the availability of card swiping facility and other modes of payment of bills

- must maintain appointments efficiently

- must manage routine activities in an efficient way

Should have features are the preferred features of customers. Following hidden expectations were captured at ' $\mathrm{XYZ}$ Diagnostic Centre’ as 'Should have’ needs.

\section{Front office workforce}

- should remember, recognize regular, loyal customers and receive them affectionately

- should not make them wait unnecessarily

- should arrange for wheelchairs and stretchers, if need be

- should make sick patients lay down in waiting room
- should provide mobile charges for customers

- should co-ordinate with other departments to get all prescribed investigations with minimum waiting period

- should inform exact cost of investigations before billing

- should provide comfortable seating arrangement

- should attend to a customer quickly

- should arrange for wheel chairs and stretchers, if necessary

- $\quad$ should attend to customers quickly

Could have opinions are "feel good" kind of feelings. Following hidden desires were collected at 'XYZ Diagnostic Centre' as 'Could have' expectations.

\section{Front office workforce}

- could be presentable with pleasing gestures (Hair-cut, daily shave, look smart)

- could provide newspapers and magazines to read

- could allow a customer to make a phone call from the reception desk in case of emergency

- could arrange a housekeeping staff to accompany the sick patients to wash rooms for collecting prescribed investigation samples

- could explain about the availability of consultant doctors and timings

- could switch on TV, AC and lights when required

- could provide some visiting cards of the organization

- could take care of the belongings of customers when they go to use wash rooms

- could provide brochures about the company without being asked

- could provide customers visiting cards of the company

"Wouldn't have" are the rejections and irritation causers for the customers and 
are the ones which the customer opine that they should not be there at all. The following negative qualities of front office workforce are the major hidden expectations of customers of 'XYZ Diagnostic Centre' under "Wouldn't have” category.

- Short-tempered staff

- Incompetent staff

- Staff with lack of commitment and disinterest

- Staff always engaged in personal talks on mobile phone

- Staff who give wrong and insufficient information

- Staff with indifferent attitude

It is to be noted that these are not the responses for feedback but are the heart-felt sentiments of customers captured through observations and interactions. This exercise encompass the front office workforce, but can be extended to all the staff who are in direct interaction with the customers like phlebotomists, pathologists, nurses, transcriptionists, accounts managers, security and housekeeping staff.

Against this backdrop, every attempt of governance, management and work-force towards addressing these hidden expectations shall enhance customer satisfaction towards achieving customer delight.

\section{CONCLUSION}

In this era of digital world, before the customers express their unpleasant experiences on social media platforms, it is of utmost importance to identify, prioritize and resolve such customer issues instantly using proactive approaches. The techniques of identification and prioritization of hidden expectations discussed in this paper, if regularly and meticulously followed, would reduce customer complaints, thereby enhancing customer delight.

The outcomes of the exercise carried out at 'XYZ Diagnostic Centre' as narrated in this paper substantiated the importance of the elicitation techniques discussed. The hidden expectations elicited during the exercise were addressed at the mentioned lab. The management of the lab did necessary corrections that resulted in improved feedback and response in subsequent customer surveys.

\section{ACKNOWLEDGEMENTS}

Sincere thanks to Dr. Govind $\mathrm{R}$ Kadambi, Pro-VC of Ramaiah University of Applied Sciences for providing motivation and research insight. We also thank the management of the diagnostics centre for giving permission to carry out ethnography and interactions with the customers as well as the staff. Special thanks to all the patients and their attenders whose hidden expectations were elicited.

\section{Conflict of Interest: None}

\section{Source of Funding: None}

\section{REFERENCES}

1. Ejeta, E., Tadele, G., Desalegn, M., Abere, S., \& Elias, K. (2015). Health care providers satisfaction with the clinical laboratory service of Nekemte Referral Hospital, Western Ethiopia. International Journal of Medicine and Medical Sciences, 7(5), 9197.

2. Satvinder Singh Bedi (2014) Impact of Healthcare services on outpatient satisfaction in Public and Private hospital: A study of hospital in Mumbai, Navi Mumbai, Thane, Pune and Surat Thesis submitted to D.Y Patil University, Navi Mumbai

3. Al-Abri R, Al-Balushi A. Patient satisfaction survey as a tool towards quality improvement. Oman Med J. 2014 Jan;29(1):3-7. doi: 10.5001/omj.2014.02. PMID: 24501659; PMCID: PMC3910415.

4. Anas-Allahham., (2013) Determinants of Customer Satisfaction in Healthcare Service International Journal of Business and Management Innovation

5. K Vidhya, Dr.C Samudhram Rajkumar, Dr.K Tamizhijyothi.,(2013) An empirical study on patient delight and the impact of human and non-human factors of service quality on patient satisfaction in private hospitals IOSR Journal of Business and Management 
6. Catherine Efuteba., (2013) Factors influencing customer satisfaction in healthcare services: The case of Public and Private hospitals in North Cyprus Document submitted to Eastern Mediterranean University

7. Teklemariam Z, Mekonnen A, Kedir H, Kabew G. Clients and clinician satisfaction with laboratory services at selected government hospitals in eastern Ethiopia. BMC Res Notes. 2013 Jan 16;6:15. doi: 10.1186/1756-0500-6-15. PMID: 23324260; PMCID: PMC3556148.

8. Koh YR, Kim SY, Kim IS, Chang CL, Lee EY, Son HC, Kim HH. Customer satisfaction survey with clinical laboratory and phlebotomy services at a tertiary care unit level. Ann Lab Med. 2014 Sep;34(5): 380-5. doi: 10.3343/alm.2014.34.5.380. Epub 2014 Aug 21. PMID: 25187892; PMCID: PMC4151008.

9. Hsiu-Yuan-Hu, Ching-Chen-Cheng, Shao-IChiu, Fu-Yua-Hong., (2011) A study of Customer Satisfaction, Customer Loyalty and quality attributes in Taiwan's medical service industry. African Journal of Business Management

10. Halil Zim, Nizamthin Bayyurt, Selim-Zaim., (2010) Service quality and determinants of Customer Satisfaction Turkish Experience. International Business and Economics Research

11. Clegg, Dai; Barker, Richard (1994). Case Method Fast-Track: A RAD Approach. Addison-Wesley. ISBN 978-0-201-62432-8

12. "MoSCoW Analysis (6.1.5.2)". A Guide to the Business Analysis Body of Knowledge (2 ed.). International Institute of Business Analysis. 2009. ISBN 978-09811292-1-1

How to cite this article: Nandini K, A. C. Lokesh. Elicitation of hidden expectations of customers in healthcare service. Gal Int $J$ Health Sci Res. 2021; 6(4): 21-25. DOI: https:// doi.org/10.52403/gijhsr.20211005 